\title{
Community College Formula Funding: A Policy Analysis Framework
}

\author{
RICHARD W. FONTE
}

In 1940 V.O. Key asked the basic budget-design question, "on what basis shall it be decided to allocate $X$ dollars to activity ' $A$ ' instead of activity ' $B$ '?' The question makes it clear that budgeting is a "decision-making" system involving a process, and an output of a value choice in the form of a resource allocation. But, what budgeting system will emerge as community colleges enter the late 1980s? The budget processes of our individual states provide different answers on both values and methodology to Key's question. This article does not attempt to answer the question, but does suggest a policy analysis framework that may be useful for both the practitioner and researcher reviewing funding approaches among community college.

Policy options are clearly the high-profile factor in most funding debates. Yet, the understanding and clarification of the decision process can be assisted through the use of formative evaluation criteria to evaluate the impacts of the suggested change in allocation technique.

The most frequent public higher education financing approach to provide state dollars to public institutions is formula funding. This is especially true at the community college level, where the formula procedure is applied to a little over two-thirds of the states (Wattenbarger and Mercer, 1985). With so many states using some form of formula funding, however, a significant area of analysis is how this allocation process in particular is being modified to address emerging policy options.

\section{Formative Evaluation}

State decision-makers, either explicitly or implicitly, engage in formative evaluation using both substantive and procedural criteria, while selecting or revising an allocation approach. Drawing upon the literature of formula funding, we find James L. Miller (1963) in his review of formula funding reported on three such formative procedural criteria. A large number of other formula funding writers have reported similar procedural criteria (Halstead, 1974; Hale and Rawson, 
1976; Moss and Gaither, 1976; Caruthers and Orwig, 1979; McClintock, 1980; Brinkman, 1984).

This framework borrows from Miller by suggesting three criteria:

- Technical Expertise: Does the formal allocation technique measure, weight, identify or qualify?

- Two-Way Feedback: Is the allocation process "open" and does it encourage and facilitate participation and the communication of views on institutional needs and state priorities between all actors in the process, i.e., legislature, governor, higher education agency and local institution.

- Values and Issues Clarification: To what extent does the allocation process highlight the value choices and the fact situation involved in any choices.

\section{Substantive Evaluation Criteria}

The writings of formula funding analysts are also filled with substantive outcome criteria. Wattenbarger $(1978,1981)$ and Garms (1977) established criteria which are excellent starting points to analyze the priority among state fundingplan goals for community colleges. Wattenbarger $(1978,1981)$ developed initially seven criteria which he used to evaluate specific funding plans ranging from negotiated line-item budgets to cost-based formulas. Likewise, Garms (1977) recommended that state community college systems be evaluated on the basis of nine funding criteria. These criteria also parallel those of others, such as Arney (1969), who have identified specific measures to assist the analysis of state funding plans.

\section{Policy Judgment Categories}

While a wide range of substantive objectives are contained in the literature, an analytical framework is assisted by considering broad, rather than ;narrow categories as separate elements for analysis. Four such categories have been summarized from the above literature of major community college finance writers, along with other formula funding authors. Both value choices and priority setting among values are involved in developing an allocation approach that addresses issues in each of these policy judgment areas. These four groupings do, moreover, provide a structure to analyze funding approaches through an impact analysis:

- Mission Diversity: What will be the method chosen to assure mission and diversity recognition? Will financing plans modify the comprehensive mission of the community college? Will finance plans facilitate or hamper the local community orientation mission of local institutions?

- Quality, Outcomes, Effectiveness: How will quality and program improvement and accountability concerns be handled? What methods would need to be adopted to specifically provide for quality improvement? What are the tradeoffs with the use of categorical grants?

- Access, Equity and Fair Share: How will equity and "fair share" concerns be addressed including equitable funding among institutions, between the student and the state, between state and nonstate sources of funding?

- Efficiency and Enrollment Linkage: What will be the nature of the link to enrollment and efficiency concerns? What tradeoffs exist with the newer formula methods based on the procedural values. 


\section{Mission Recognition and Differentiation}

Funding formulas have often been criticized for having a "leveling" effect on institutions (Gross, 1973) and a corresponding lack of recognition of differences in mission. According to Brinkman (1984), "if treated alike for a long enough period, diverse institutions will become similar."

Two elements are generally considered critical to overcome "leveling" through a system of differential funding. The funded units included in the formula should be "cost based,"and programs and service levels should be identified into separate categories. Costs are usually determined through technical studies, but at times, especially at the community college level, the differentiation is a normative decision. Differentiated funding contrasts with single unit rate or flat grant funding. Among community colleges, level differentiation is still the exception. Analyses of Wattenbarger $(1983 ; 1985)$ and Stumph (1984) find approximately eighteen of thirty-seven formula states using differentiated as opposed to flat-rate grants. Yet, Warren, et al (1976) found differentials critical to "high-equipment-centered" occupational curricula at the community college level.

The Illinois Formula, for example, has also attempted to reinforce certain missions by the use of category "program" grants. Economic Development and Advanced Technical and Disadvantaged Student category grants are all attempts to reinforce state priorities and to clarify the high value placed on these activities by the state.

Formative Evaluation: Wattenbarger (1985) considers program cost-differentiated formulas as significantly superior to other types in advancing the overall mission of community colleges. The use of formative evaluation criteria, however, suggests the necessity of studying the tradeoff between increased technical expertise and the technique's impact on communicating values among the participants due to the added complication inherent in the technique. For example, Breneman and Nelson in 1981 reported on a previously used, thirty-one cost category Florida formula. Garms (1977), as well as Breneman and Nelson, argues that the number of categories for differential support rates, at least at the community college level, should be kept relatively low, somewhere in the range of five to ten (Garms, 1977; Breneman and Nelson, 1981). Both studies also suggest a difficulty of meeting the criteria of "technical expertise" with the increased cost of accurate and regular cost studies if there are too many categories. The use of special categorical "program" funding has the particular strength of "mission recognition" reinforcement through their ability to clearly communicate the policy choices and perhaps to encourage a dialogue among participants. The tradeoff appears to be the assumption of significant state agency involvement. In Illinois, however, the percentage allocated through this method is relatively small and the allocations are driven by formula that limits the state agency's discretion.

\section{Quality and Program Improvement}

In most states "quality of performance or outcomes of the educational process were not recognized" in the multipurpose, general allocation formula (Folger, 1984a; Jones, 1984b). "The exclusion of performance criteria," Folger suggests, "is not a matter of simple oversight." Most states have left quality maintenance as the responsibility of individual institutions. 
If states begin to include quality or performance criteria in the budget process, they must become involved in the definition of effectiveness and in the measurement of performance and the establishment of quality or performance objectives (Folger, 1984).

Jones (1984b) recommends that a special purpose, rather than multipurpose, budget component should be utilized for states seeking means to include quality factors into its funding formula. One example, the Tennessee project, perhaps has received the greatest publicity permitting up to an additional two percent of the budget allocation of each institution to be based on performance and quality indicators (Pickens, 1983).

Ohio, on the other hand, has recently developed through its multipurpose component a supplemental quality improvement program, Academic Challenge, providing automatically one percent additional to the institution to be used in any area they designate for improvement for a six-year period (Coulter).

In most cases the total percentage of budget affected by program improvement formula factors is relatively small. The approach does, however, help overcome several significant criticisms of formula funding (i.e., the anti-innovation criticism).

Formative Evaluation: The research questions arising from this policy judgment category are quite similar to that of mission recognition and include the analysis of trade-off of institutional autonomy, communication of values, and whether the process encourages a collegial participatory process among actors.

\section{Equity and "Fair Share" Process}

Equity and a "fair share" process has a variety of meanings when applied to community college funding plans. One objective of equity or fairness in the distribution of state government appropriations for higher education is to provide the same funds to any institution for each FTE enrolled in a comparable program of instruction. Formulas assist institutional fair-share equity by calculating budget requests of institutions according to the same set of procedures, i.e., maximizing technical expertise in an open process. They provide an objective basis for determining institutional "fair share" (Meisinger, 1976); but, as Miller (1963) states, "the use of objective procedures employing objective (quantitative) data does not alter the fact that value decisions are made" or that formulas are "a combination of technical judgments and political agreements" (Mesinger, 1976).

While traditional incremental budgeting offers the advantage of flexibility in factor usage in comparison to formula funding, this flexibility also can mean that the ground rules are not as explicit for anything other than an "equitable" straight percentage increment (or decrement) approach (see Wildavsky, 1975). In formulas a heavy dose of politics is confined to the design stage (Jones, 1984a), while with incrementalism or negotiated budgeting, the process is open to log-rolling and interest group politics throughout more of the stages (Morgan, 1984).

\section{Tuition "Fair Share" Contribution}

The appropriate division of cost between the student and state is a very broad topic beyond the scope of this analysis. It is, of course, at the very heart of the issue of access which has always been a major concern of community college financing. The "public benefit" derived from subsidizing the student's share is ultimately "in the eyes of the beholder ... the evaluation is political" (Breneman, 1981). Lombardi (1976) declared the "no tuition policy," a lost cause, suggesting a 
tactical retreat to a "low tuition policy." While the exact percentage definitions of "low," "moderate," and "high" tuition are open to debate in the literature, many writers classify "low" tuition states as those charging somewhere in the range of fifteen percent to twenty percent, while the borderline between moderate and high falls between twenty-five percent and thirty percent (see for example, Arney, 1969).

Viehland, et al, (1981) found "seventeen states have established policies that index tuition and overall state support." A key factor in consideration of the appropriateness of tuition indexing by formula funding designers will be the value placed on state regulation versus open-market values by decision-makers.

\section{State versus Local "Fair Shares"}

Breneman (1981, pp. 39-54) suggests the use of economic analysis in the calculation of "public benefit" and the state versus local nature of that "public benefit" to determine "fair share" division and the equitable local share of financing community colleges. Breneman concludes that, "user charges (tuition) represent the most efficient way to finance activities that possess only private benefits." For some community services from which the local community can also be the beneficiary, the local college district should provide the subsidy rather than the state. In the case of remedial courses, he suggests the public benefit is so exceptionally strong that it should be funded at full cost by state government as an investment to "reduce income-transfer expenses" in the future.

\section{Equity of Local Tax Resources}

Breneman (1981) and Garms (1981) have both looked at the equity issue in terms of differences in property wealth among community college districts giving rise to inequities in resources per student. One approach advocated by a number of authors (Wattenbarger and Starnes, 1976) is "full" state funding. For states that have local components, however, Breneman and Garms recommend inclusion of equalization concepts in the funding plan.

Most equalization concepts have been borrowed directly from the elementary and secondary school level. This component is included in Garms' (1981) findings but is not totally appropriate. Borrowing from the elementary and secondary level, the community college equalization plans attempt to equalize tax revenue available per full time equivalent (FTE) student, as the elementary/secondary approach equalizes tax revenue per student. One significant conceptual problem with this approach is that while "all elementary-secondary schools have great similarity in curricular offerings, community colleges differ widely."That is, there are differences by district in student program needs with different costs. Garms suggests the concept of a cost-sensitive weighted FTE, rather than simply borrowing a procedure that is not entirely transferable from the elementary/secondary level.

Formative Evaluation: The allocation technique adopted in this policy judgment area suggests the need for research not only on the technical expertise of the approach, but also on the impact of the method of communicating and clarifying basic values and facts among the participants in the process and secondly encouraging an open two-way participatory dialogue among the actors in the process. 


\section{Enrollment Linkage to Resource Allocation}

Many writers have suggested and demonstrated that enrollment-based funding approaches are legacies of the growth era (Boutwell, 1973; Jones, 1984a; Moss and Gaither, 1976; Yeager and Linhart). In particular, during growth periods the real cost of one additional student, the marginal cost to the institution, is less than the average cost of a student. In times of enrollment decline, however, institutions can incur disproportionate funding losses, exceeding the real cost reduction of a loss of one student. That is, the decrease of one student in a class of one hundred does not result in a one percent saving in the cost of teaching that class because of institutional fixed costs that are not directly enrollment-related (Gross, 1979; Hale and Rawson, 1976).

\section{Formula Allocation for Instruction Costs-The Traditional Methods}

The enrollment-based formula approach calculates allocations by multiplying some workload measure of enrollment such as head count, or more frequently, FTE student or credit-hour by a dollar rate "that may be normative (negotiated or politically determined) or analytically derived (a technical judgment based on cost studies)" (Jones, 1984a). The most obvious use of this type of formula is to determine instructional cost, the largest single cost item of a college. Enrollmentbased allocation factors can also be used to calculate the costs beyond instruction, using instructional costs as the "base" and the expenditures of other functional areas as fixed percentages of this base (Halstead, 1974). The question is how many of these functions utilize enrollment-related workload measures, directly or indirectly, to determine funding. The degree to which a state's overall funding is "enrollment-driven," depends on the answer to this question.

\section{Decoupling}

As one alternative, "decoupling," or the use of nonenrollment-based factors for the noninstructional, functional cost areas has been recommended by a number of authors as a growing and desirable trend (Spence and Weathersby, 1981; Brinkman, 1984). The operations and maintenance function, in particular, has been singled out for this approach. Miller (1963) suggested that "the costs of building maintenance are affected less by changes in number of students than by changes in the number and condition of the buildings themselves." The Michigan community college formula uses different base factors for both energy and physical plant funding. Overall, however, a review of Wattenbarger's analyses $(1983,1985)$ found that out of the thirty-seven community college formula states, approximately twelve used different rate calculations for any separate cost functions. Frequently, a single calculation base, an enrollment-related, "unit cost," is used to generate the entire budget allocation.

\section{Buffering}

Unlike "decoupling," the objective of "buffering" is not to remove the link for some functional cost area, but rather to weaken the link through a variety of means such as creating enrollment "corridors," "enrollment thresholds," or averaging enrollments or cost-formula factors over several years (Jones, 1984a; Brinkman, 1984). Wattenbarger (1985) found multiyear averaging an emerging and desirable 
trend. Overall, most "buffering" arrangements have the effect of "buying time," evening out fluctuations but not fundamentally changing the funding concepts (Jones, 1984a, p. 73).

\section{Marginal and Fixed Cost Funding}

While "decoupling" and "buffering" can be considered indirect methods to modify the adverse impact of an average cost-funding formula, under the use of marginal cost techniques, funding remains linked to enrollment but by a new methodology, which while "sensitive to enrollment changes ... is not as sensitive as linear (average cost) formulas" (Monical and Schoenecker, 1980). As an example, among California community colleges, funding for additional students is provided at a rate that is two-thirds that of the average revenue-per-student in the state, "the assumption is that marginal costs are less than average cost by about one-third" (Brinkman, 1984).

Fixed-variable costing can be seen as special type of marginal costing. Jones (1984a) states that unlike the other approaches to desensitizing funding from enrollment, this approach explicitly "recognizes the necessity of developing and maintaining a core institutional capacity." That is, the state has a basic responsibility to maintain its investment at some threshold level beyond immediate annual enrollment.

Formative Evaluation: As formula states consider adoption of new approaches, such as "decoupling," "buffering," "enrollment corridors," or "marginal and fixed cost approaches" to lessen the hold of enrollment over funding, questions arise not only as to the technical correctness of the approach but also as to whether these approaches add a complexity to the funding technique that interferes with desirable procedural or process values. Paul Brinkman (1984) found, for example that "decoupling," along with other recent changes, had the advantage of making formulas much more complex. Likewise, both technical expertise questions and political problems stand in the way of states widely adopting marginal costing techniques. In fact, Indiana eventually selected a consensual judgment rather than a statistical approach, since they admitted that "there is no conclusive evidence to support specific fixed cost factors" (Allen and Topping, 1979; Brinkman, 1984; Jones, 1984a).

\section{Conclusion}

With seventy-four percent of all state community college systems based upon formula, at the very least, we must admit that formulas have retained their appeal. The continued satisfaction with this approach, however, will depend upon the extent that formulas are revised successfully to handle issues arising from four policy categories: enrollment linkage, mission recognition, equity and fair-share considerations, and provisions for quality and program improvement. While these policy judgment categories will be the general focus of attention, the understanding and clarification of the decision process will be assisted by analyzing the interaction of proposed changes in the allocation technique with principles of formative evaluation. This framework is intended to provide some tools to analyze these interactions and help the decision-maker in attempting to answer value questions that arise in the policy categories. 


\section{References}

Allen, R. H. and Topping, J. R. (1979). Cost information and formula funding: New approaches. Boulder, Colorado, National Center for Higher Education Management Systems.

Arney, L. H. (1969). A comparison of patterns of financial support with selected criteria in community junior colleges. Unpublished doctoral dissertation, The University of Florida, Gainesville, Florida.

Boutwell, W. K. (1973). Formula budgeting on the down side. In G. Kaludis (Ed.). Strategies for budgeting. San Francisco, California: Jossey-Bass, Inc.

Breneman, D. W. and Nelson, S. C. (1981). Financing community colleges: An economic perspective. Washington, D. C.: The Brookins Institute.

Brinkman, P. T. (1984). Formula budgeting: The fourth decade. In L. L. Leslie (Ed.). Responding to new realities in funding. San Francisco, California: Jossey-Bass, Inc.

Caruthers, J. K. and Orwig M. (1979). Budgeting in higher education. Washington, D.C. P: American Association for Higher Education.

Coulter, W. G. (1985). Ohio steps out front ... an investment in excellence. Columbus, Ohio: Ohio Board of Regents.

Folger, J. (1984a). Editor's notes. In J. Folger (Ed.). Financial incentives for academic quality. San Francisco, California: Jossey-Bass, Inc.

Folger, J. (March, 1984b). How can states budget for quality? Paper presented at the Annual Meeting of the Association for the Study of Higher Education, Chicago, Illinois, March, 1984b.

Garms, W. I. (1981). Perspective on measuring the equity of community college finance. Educational Administration Quarterly, 17, 1-20.

Garms, W. I. (1977). Financing community colleges. New York, New York: Teachers College Press, Columbia University.

Gross, F. M. (1979). Formula budgeting and the financing of public higher education: Panacea or nemesis for the 1980s? AIR Professional File, 3, 21-31.

Gross, F. M. (1973). A comparative analysis of the existing budget formula used for justifying budget requests or allocating funds for the operating expenses of statesupported colleges and universities. Knoxville, Tennessee: Office of Institutional Research, University of Tennessee.

Hale, J. S. and Rawson, T. M. (1976). Developing statewide higher education funding formulas for use in a limited growth environment. Journal of Education Finance, 2, 16-32.

Halstead, D. K. (1974). Statewide planning in higher education. Washington, D.C.: United States Government Printing Office.

Jones, D. P. (1984a). Higher education budgeting at the state level: Concepts and principles. Boulder, Colorado: National Center for Higher Education Management Systems.

Jones, D. P. (1984b). Budgeting for academic quality: Structures and strategies. In J. Fogler (Ed.). Financial incentives for academic quality. San Francisco, California: Jossey-Bass, Inc.

Key, V. O., Jr. (1940, December). The lack of a budgetary theory, The American Political Science Review, XXXIV, 1137-1144.

Lombardi, J. (1976). No or low tuition: A lost cause. Topical Paper No. 58. Los Angeles, California: ERIC Clearinghouse for Junior Colleges.

McClintock, D. L. (1980). Formula budgeting: An approach to facilities funding. Washington, D. C.: Association of Physical Plant Administrators of Universities and Colleges.

Meisinger, R. L., Jr. (1976). State budgeting for higher education: The uses of formulas. Berkeley, California: Center for Research and Development in Higher Education, University of California. 
Miller, J. L., Jr. (1963). State budgeting for higher education: The use of formulas and cost analysis. Unpublished doctoral dissertation, University of Michigan. Ann Arbor, Michigan.

Monical, D. G. and Schoenecker, C. V. (1980). Marginal funding: A difference that makes a difference? Research in higher education, 12, 67-82.

Morgan, A. W. (1984). The new strategies: Roots, context, and overview. In L. L. Leslie (Ed.). Responding to new realities in funding. San Francisco, California: Jossey-Bass, Inc.

Moss, C. E. and Gaither, G. H. (1976). Formula budgeting: Requiem or Rennaissance? Journal of Higher Education, 47, 543-563.

Pickens, W. H. (1983). Performance funding in higher education: Panacea or peril? In R. A. Wilson (Ed.). Survival in the 1980s: Quality, mission and financing options. Tucson, Arizona: Center for the Study of Higher Education, University of Arizona.

Spence, D. S. and Weathersby, G. B. (1981). Changing patterns of state funding. In J. R. Mingle et al (Eds.). Challenges of retrenchment. San Francisco, California: JosseyBass, Inc.

Stumph, W. J. (1984). Financing community colleges-the several ways. Paper presented at meeting of the Association of School Business Officers, Atlantic City, New Jersey, October, 1984.

Viehland, D. et al (1981). Indexing tuition to cost of education: Implications for state policy. In L. Leslie and J. Hyatt (Eds.). Higher education financing policies: States/ institutions and their interaction. Tucson, Arizona: Center for the Study of Higher Education, University of Arizona.

Warren, J. T. et al (1976). Differential costs of curricula in Illinois public junior colleges: Some implications for the future, Research in higher education, 4, 59-67.

Wattenbarger, J. L. (1985). Dealing with new competititon for public funds: Guidelines for financing community colleges. In W. L. Deegan and D. L. Tillery (Eds.). Renewing the American community college. San Francisco, California: Jossey-Bass, Inc.

Wattenbarger, J. L. and Stepp, B. (1978). Financing community colleges 1978. Gainesville, Florida: Institute of Higher Education, University of Florida.

Wattenbarger, J. L. and Bibby, P. (1981). Financing community colleges 1981. Gainesville, Florida, Institute of Higher Education, University of Florida.

Wattenbarger, J. L. and Mercer, S. L. (1985). Financing community colleges 1985. Gainesville, Florida: Institute of Higher Education, University of Florida.

Wattenbarger, J. L. and Heck, J. (1983). Financing community colleges, 1983. Gainesville, Florida: Institute of Higher Education, University of Florida.

Wattenbarger, J. L. and Starnes, P. M. (1976). Financial support patterns for community colleges. Gainesville, Florida: Institute of Higher Education, University of Florida.

Wildavsky, A. (1975). Budgeting: A comparative theory of budgetary processes. Boston, Massachusetts: Little Brown \& Company.

Yeager, J. I. and Linhart, C. A. (1978, May). Adequacy of budget formulas for balancing institutional needs and resources in nongrowth periods. Paper presented at the annual Association for Institutional Research Forum, Houston, Texas, May, 1978.

Richard W. Fonte is Vice President for Budget Planning and Development, Triton College, River Grove, Illinois, and is a doctoral student in Education Administration at the University of Michigan, Ann Arbor, Michigan. 